\title{
Infection among Women using Intrauterine Devices and Oral Contraceptives
}

Aida abd El-Razek,

Assistant Professor of Maternal and newborn Health Nursing

Faculty of Nursing, Menoufyia University

\begin{abstract}
The aim of the present study is to evaluate the relationship between vaginal douching practices and genitourinary infection in women, aged 18-49, who use an intrauterine contraceptive device (IUCD) or oral contraceptives (OCP). This study was planned and applied as a descriptive cross-sectional study. The study was conducted at Mother and Child Health and Family Planning Center of El-Basher Hospital Amman Jordon. The study was conducted with 185 consenting women (90 using OCP, 90 using IUCD). Since the number of women using condoms was minimal, these were excluded from the study. 10 months at 2009 over the period of the study. No inclusion criteria were taken into consideration aside from age, having used the same method in the last 4 years, and not menstruating at the time samples were to be taken. It was found that women taking OCP who practiced vaginal douching (VD) had higher ratios of bacteria growth in the urine compared to women with IUCD. While there was a significant relationship seen between the method used and the urine culture results $\left(\mathbf{X}^{2}=5.045 \mathrm{df}=1 \mathrm{p}=0.01\right)$, no relationship was observed in terms of the vaginal culture $\left(\mathbf{X}^{2}=0.631 \mathrm{df}=1 \mathrm{p}=0.264\right)$. The conclusion of the study was that the development of genitourinary infection during the use of OCP or IUCD was associated more with lack of proper hygiene rather than with the practice of vaginal douching.
\end{abstract}

Keywords: Genitourinary infection, Intrauterine contraceptive device, Oral contraceptive, Vaginal douching 


\section{Introduction}

Vaginal douching (VD) is an old and traditional practice that is carried out for intra-vaginal cleansing or treatment, using the fingers and/or substances to clean and rinse out the vagina $\left.{ }^{[1,} 2\right] . \quad V D$ is a widespread practice among women. Woman practice VD generally for vaginal cleanliness after menstruation or sex, as a contraceptive measure, or because of hygienic beliefs ${ }^{[3]}$. According to hygienic belief, body secretions flowing from or remaining in the vagina preclude the observance of hygienic beliefs. Menstruating women, for example, cannot perform the ritual prayer or read the Koran ${ }^{[4]}$. Most women will clean the vaginal area after sexual intercourse, either using their fingers or by douching, removing seminal fluid from the vagina as an act of purification ${ }^{[4,5]}$. Women use many different substances when practicing VD. Among the most frequently encountered of these are soap, perfumes, and vinegar $\left.{ }^{[6,} 8\right]$. In addition, some studies have reported that women are not aware of the harmful effects of $\mathrm{VD}^{[7,8,9]}$. When the habit of washing out the genital area with water after going to the toilet is added to the practice of $\mathrm{VD}$, the risk of infection becomes more alarming ${ }^{[5]}$. It has been found that one-fifth of women practicing VD do so after going to the toilet.10 Women who wash the anal area after defecation are likely to perform VD with their contaminated hands. This causes the transmission of many pathogenic microorganisms into the vagina, making the area susceptible to the development of many health issues ${ }^{[11,12]}$. VD disrupts the balance of the normal vaginal flora and prepares a foundation for infection ${ }^{[10]}$. The risk of genitourinary infection increases when women's poor hygienic habits are added to this picture. It has been determined in research that methods of contraception can be trigger factors for infection. It is recognized that among the different contraceptive methods, the IUCD is the method that is more likely to increase susceptibility to genitourinary infections [13, 14]. IUCDs may change the nature of the vaginal flora and cause an increase of anaerobic bacteria ${ }^{[15,16]}$. Besides this 
shortcoming, it has also been reported that a lack of hygienic conditions during the insertion of the IUCD and deficiencies in information concerning its use are also infection-triggering factors ${ }^{[17,18]}$.

\section{Significant of the study}

According to the reports of Jordon Population and Health Research (JNSA), a significant increase was seen in the use of IUCDs as an effective method of contraception between the years 2003-2008, and it is striking to note that women with IUCDs are more educated than those that take OCPs ${ }^{[21]}$. study reported that IUCD's were the primary and preferred effective method; condoms were the second preference while taking OCPs was third ${ }^{[21]}$. The results of the present study are consistent with this finding.

Studies have shown that deficiencies in hygiene when using the various contraceptive methods are more likely to bring about genitourinary infection ${ }^{[15]}$. There is no study in the literature, however, that examines the association between the use of OCP and genitourinary infection. Some studies have been reported that the effect of OCP use on the vaginal flora is minimal ${ }^{[14,17]}$. It has been reported, on the other hand, that the estrogen contained in OCP facilitates the population of uropathogens in the vaginal and urogenital cells, preparing a suitable environment for the growth of microorganisms ${ }^{[15]}$. In addition to these factors, personal habits of the individual during the use of OCPs (anal sex, poor hygiene, low water consumption, etc.) also trigger genitourinary infection ${ }^{[16]}$.

\section{The aim of the study}

Evaluate the relationship between vaginal douching practices and genitourinary infection in women, aged 1849 , who use an intrauterine contraceptive device (IUCD) or oral contraceptives (OCP).

\section{MATERIALS AND METHOD}

\section{Research design:}

This study was planned and applied as a descriptive cross-sectional study

\section{Research Setting:}

The study was conducted at Mother and Child Health and Family Planning Center of El-Basher Hospital Amman Jordon. 


\section{Subjects of the study}

\section{Sample size}

El-Basher Hospitals, Family planning services in Jordon are provided by three separate groups of institutions. These are private and state hospitals, family physicians, and the Child Health and Family Planning Centers (CHFPC).

The CHFPC in the city center accepts a monthly average of 60 women for IUD checkups, 50 women for IUCD insertion, 70 women for OCP prescriptions, and 15 women to obtain condoms. 10 months at 2009 over the period of the study, 195 women applied to the Center and of these, 15 were using condoms. The study was conducted with 185 consenting women (90 using OCP, 90 using IUCD). Since the number of women using condoms was minimal, these were excluded from the study. No inclusion criteria were taken into consideration aside from age, having used the same method in the last 4 years, and not menstruating at the time samples were to be taken.

\section{Type of sample A}

Convenience sample of 180 using OCP, 90 using IUCD was conveniently selected to achieve the aim of the study.

\section{Tools for data collection:}

The data was collected by using penand-paper self-report forms which included the following: a socio-demographic data collection form, a questionnaire inquiring into vaginal douching behavior and data on urine culture and vaginal culture results based on the specimens obtained from the women.

The data collection form consisted of 15 questions prepared by the researchers to record the socio-demographic characteristics of the participants and the questionnaire was based on 13 questions from the literature 12 that were developed to inquire about descriptive characteristics related to vaginal douching and genital hygiene. In addition, specimens were obtained from the women for vaginal cultures and urine cultures. These samples were sent to the El-Basher Technical University Microbiology and Pathology Labs within 1hour. Sociodemographic Questionnaire

This consisted of questions developed by the researcher based on the 
Literature.The questions concerned the women's ages, their work, educational level, social security status, monthly income, number of children and births, the duration the method had been used and similar information.Vaginal Douching and General Hygiene Questionnaire

This consisted of questions about vaginal douching practices, the method used, the reason for practicing $\mathrm{VD}$, from whom the woman had heard about vaginal douching, the material used in VD, how frequently it was practiced, how many times the woman has sex in a week, and whether or not she had any knowledge about the harmful effects of VD.

\section{Ethical Considerations:}

The study was carried out with co-operation of different levels of authority. An official letter was sent from the Dean of the Faculty of Nursing in Philadelphia University to the directors of El-Basher Hospitals These are private and state hospitals, family physicians, and the Child Health and Family Planning Centers (CHFPC) explaining the aim of the study and the time of data collection seeking his permission for data collection. An official permission through written letters clarifying the purpose and sitting of the study was obtained from the directors of El-Basher Hospital As an approval for data collection. A written informed consent was obtained from the participants after explaining the purposes of the study, which include: no harm was occurring to participant, do not contradict with the cultural, traditional and religious issues, human rights were reserved, data was confidential and used mainly for the purpose of the research and each subjects was free to withdraw from the study at any time.

\section{Method}

\section{Data collection Procedure:}

- Development of tools for data collection after reviewing the related

- literature the tools was revised for content validity by 5 experts in the field.

- The women's was selected by A convenient sample was used according to the mentioned criteria.

- The data were collected through a period of 10 months at 2009. Three days per week starting at $9 \mathrm{am}$ to 


\section{Tanta Scientific Nursing Journal}

$2 \mathrm{pm}$. The researcher introduced herself to the women and obtained their consent to be recruited in the study after explaining the aim of the study.

- Each woman was interviewed individually by the researcher.

- The average time for filling each sheet was about 15 minutes depending on the response of the women. Consent was obtained from each women and the interviewing questionnaire was explained to each women.

- After that, the researcher assessed Procedure for Obtaining Sterile Urine Specimens. A sterile container (red-screw-capped culture container) was used as a urine culture container.

- Instructions as to how the culture should be taken were given to the women consenting to the study, as follows: "Thoroughly wipe the outer part of the urinary tract with the disinfectant/antiseptic wipe before taking the urine sample; dry the area with the sterile gauze that's been given to you; after discharging the first few drops of urine, collect the middle of the flow in the sterile container. Do not allow the urine container to touch anything and do not fill up the container to the brim." [20].

- The lids were then placed on the urine containers, on which the names of the patients were written; the specimens were taken to the laboratory in a short time by the researcher. The samples were evaluated after their "S"-shaped inoculation on to blood EMB/McConkey agar plates ${ }^{[20]}$.Procedure for Obtaining Vaginal Culture: Glass culture tubes equipped with cotton-tipped sterile swabs used only for this purpose were employed to gather specimens. The small-tipped sterile swab was swept across the vaginal wall and the specimen was placed in a closed container with the patient's name written on it. A Nugent score assessment of the samples was made $^{[20]}$. 


\section{Limitation of the study:}

Microbiology and pathology laboratories

container is not available for sometime.

Not funded this study by the University

Research, researcher finds it difficult to test

\section{Statistical Analysis}

The Statistical Program for the Social Sciences, version 15.0 (SPSS 15.0) was used for data analysis. Percentages and averages were also calculated, the Chi-square test and $\mathrm{t}$ - test were performed for the statistical analysis. The level of statistical significance was set at $\mathrm{p}<0.05$.

The logistic regression analysis model to determine which factors affected bacterial growth in the urine and vaginal culture. The enter method was used in the logistic regression analysis

\section{RESULTS}

The women's age group, their working status, educational level, social security status and income levels are shown in Table 1. As can be seen in Table 1, no statistical difference was observed between the two groups except variable of educational level. The women taking OCPs made up $70 \%$ of the group, and those using IUCD's, $81.1 \%$.
In the statistical analysis, there was no significant difference between the two groups in terms of performing vaginal douching $\left(\mathbf{X}^{2}=7.716 \mathrm{p}=0.120\right)$ (Table 2). It was found that $63.5 \%$ of the women practicing vaginal douching who were taking OCPs, $68.5 \%$ of the women using IUDs said that they practiced VD 2-3 times a week; $41 \%$ of the women using IUCDs said that they had made this decision on their own; $46 \%$ of the women using OCPs said they had heard about VD from their elders; $68.3 \%$ of the women taking OCPs said that they performed vaginal douching with soap and water, and $65.8 \%$ of the women with IUDs said that they performed vaginal douching with water; of the women using OCPs, $47.6 \%$ said they performed VD usually after sexual intercourse; $61.6 \%$ of the women with IUCDs said they performed vaginal douching after menstruation; $60.3 \%$ of the women taking OCPs and $65.8 \%$ of the women using IUCDs stated that they practiced vaginal douching regularly. Of the women taking OCPs, $71.4 \%$, and $68.5 \%$ of the women using IUCDs said they didn't think VD was 
harmful (Table 2). There were significant differences between the groups in terms of the materials used regularly, the method of VD and the frequency of sexual intercourse $\left(\mathbf{X}^{2}=18.77 \quad \mathrm{p}=0.000 ; \quad \mathbf{X}^{2}=7.35 \quad \mathrm{p}=0.020 ;\right.$ $\mathbf{X}^{2}=29.02 \quad \mathrm{p}=0.000 ; \quad \mathbf{X}^{2}=8.37 \quad \mathrm{p}=0.000$, respectively).

Among the group taking OCPs, $78.9 \%$, and $65.6 \%$ of the IUCD group were rinsing off their genital area from back to front. A statistical difference was found in this factor between the groups $\left(\mathbf{X}^{2}=6.211 \mathrm{p}=0.001\right)$ (Table 3). The two groups also exhibited significant differences in terms of the material used for drying off, continuously using a sanitary pad, and the existence of a disagreeable secretion $\left(\mathbf{X}^{2}=5.91 \mathrm{p}=0.011\right.$; $\mathbf{X}^{2}=18.55 \quad \mathrm{p}=0.000 ; \quad \mathbf{X}^{2}=2.188 \quad \mathrm{p}=0.000$, respectively) (Table 3). It was noted that $75.6 \%$ of the OCP group dried off their genitals after going to the toilet while this percentage was $86.7 \%$ in the IUCD group. There was no significant difference found between the two groups $\left(\mathbf{X}^{2}=1.494\right.$ $\mathrm{p}=0.149$ ). Looking into whether the women wore cotton underwear, it was seen that 83.3 $\%$ of the OCP group and $77.8 \%$ of the IUCD group wore cotton underwear; no significant difference was found between the two groups $\left(\mathbf{X}^{2}=2.414 \mathrm{p}=0.08\right)$ (Table 3$)$. As regards the practice of using sanitary protection all the time, it was revealed that $74.4 \%$ of the OCP women and $35.6 \%$ of the IUCD group used sanitary pads daily. A significant difference was found between the two groups $\left(\mathbf{X}^{2}=18.55 \mathrm{p}=0.00\right)$ (Table 3). Daily water consumption of less than 2 liters was $55.6 \%$ in the OCP group and $50 . \%$ in the IUCD group there was a significant difference found between the two groups in terms of this factor $\left(\mathbf{X}^{\mathbf{2}}=9.956 \mathrm{p}=0.007\right)$.

Tabe 4: While bacterial growth was observed in the urine culture results of $53.1 \%$ of the women taking COCs, bacterial growth was found in $35.7 \%$ of the women with IUCDs. Escherichia coli was the microorganism predominantly found in the urine culture of women taking OCPs, while Enterobacteria species were more pronounced in women with IUCDs. The results of the vaginal culture showed that $66.7 \%$ of the women using OCP and $60.7 \%$ of the women using IUCD's did not display any microbial growth. In the vaginal culture, 
both groups of women displayed a predominant growth of the microorganism Candida albicans. While there was a significant difference between the two groups in the urine culture results $\left(\mathbf{X}^{2}=5.045\right.$ $\mathrm{p}=0.01$, no difference was discovered in the vaginal culture $\left(\mathbf{X}^{2} 2=0.631 \mathrm{p}=0.264\right)$.

The results of the logistic regression analysis used to determine the factors that had an effect on the urine and vaginal culture are shown in Tables 4 and $\mathbf{5}$. As can be seen in Table 4, the use of OCPs (Exp: 0.12, 95\% CI 0.01-0.91), wiping from back to front (Exp: 8.66. 95\% CI 1.54-48.95), continuous use of a sanitary pad (Exp:
59.99, 95\% CI 40.83-7.68), low daily water consumption (Exp: 68.94\% CI 6.21-75.98), engaging in sexual intercourse 3-4 times a week (Exp: 0.203, 95\% CI 0.55-0.75), using a piece of cloth hand-sewn at home as drying material (Exp: 0.158, 95\% CI 0.021.22) were seen to be independent factors that had on an effect on bacterial growth in the urine culture, while the use of IUCDs (Exp: 1.07, 95\% CI 0.49-2.35) and performing vaginal douching (Exp: 6.47, $95 \%$ CI 0,97-42.74) were independent factors observed to have an effect on bacterial growth in the vaginal culture

Table (1): Percentage distribution of identifying characteristics according to their general characteristics and obstetrical history.

\begin{tabular}{|c|c|c|c|c|c|c|}
\hline \multirow{3}{*}{$\begin{array}{c}\text { Variables } \\
\text { General characteristics }\end{array}$} & \multicolumn{4}{|c|}{ Groups } & \multirow{3}{*}{$\mathrm{X}^{2}$} & \multirow{3}{*}{$\mathbf{P}$} \\
\hline & \multicolumn{2}{|c|}{$* \mathrm{OCP}=90$} & \multicolumn{2}{|c|}{$* * \mathbf{I U D C}=90$} & & \\
\hline & No & $\%$ & No & $\%$ & & \\
\hline Age / year & & & & & & \\
\hline$<20$ & 18 & 20 & 20 & 22 & 2.349 & 0.503 \\
\hline 20- 25 & 28 & 31 & 30 & 33 & & \\
\hline 26- 30 & 20 & 22 & 25 & 27.8 & & \\
\hline 31-35 & 24 & 26.7 & 15 & 16.7 & & \\
\hline Occupation & & & & & & \\
\hline Hose wife & 25 & 27.8 & 15 & 16.7 & 5.789 & 0.122 \\
\hline Working & 65 & 72.2 & 75 & 83.3 & & \\
\hline $\begin{array}{c}\text { Educational level } \\
\text { Primary }\end{array}$ & 15 & 16.7 & 20 & 22.2 & 15.612 & 0.004 \\
\hline
\end{tabular}


Tanta Scientific Nursing Journal

\begin{tabular}{|c|c|c|c|c|c|c|}
\hline Secondary & 45 & 50 & 55 & 61.1 & & \\
University & 30 & 33 & 15 & 16.7 & & \\
\hline Monthly Income & & & & & & \\
500-1000 (Middle-class) & 43 & 47.8 & 23 & 25.5 & 4.160 & 0.125 \\
1001-1500 (With means) & 33 & 36.6 & 53 & 58.9 & & \\
1501-3000 (Very wealthy) & 14 & 15.6 & 14 & 15.6 & & \\
\hline Obstetrical history & \multicolumn{5}{|l|}{} & \\
\hline Gravidity & 56 & 62.2 & 66 & 73.3 & 4.267 & 0.167 \\
$1-2$ & 34 & 37.8 & 24 & 26.7 & & \\
$\geq 3$ & 2 & 2.2 & 1 & 1.1 & 3.870 & 0.005 \\
\hline Parity & 54 & 60 & 65 & 72.2 & & \\
Non & 34 & 37.8 & 24 & 26.7 & & \\
$\geq 3$ & & & & & & \\
\hline 1-2 & 50 & 55.6 & 64 & 71.1 & 3.876 & 0.652 \\
N-4 child & 35 & 38.9 & 22 & 24.4 & & \\
\hline Number of children & 5 & 5.5 & 4 & 4.4 & & \\
\hline
\end{tabular}

*OCP: Oral Contraceptive

**ICUD: Intrauterine contraceptive device

Table 2: Percentage distribution of Descriptive characteristics according to vaginal douching

\begin{tabular}{|c|c|c|c|c|c|c|}
\hline \multirow{3}{*}{ Variables } & \multicolumn{4}{|c|}{ Groups } & \multirow[b]{3}{*}{$\mathbf{X}^{2}$} & \multirow[b]{3}{*}{$\mathbf{P}$} \\
\hline & \multicolumn{2}{|c|}{$* \mathrm{OCP}=90$} & \multicolumn{2}{|c|}{$* * \mathrm{IUDC}=90$} & & \\
\hline & No & $\%$ & No & $\%$ & & \\
\hline $\begin{array}{c}\text { Practicing vaginal douching } \\
\text { Yes } \\
\text { No }\end{array}$ & $\begin{array}{l}63 \\
27\end{array}$ & $\begin{array}{l}70 \\
30\end{array}$ & $\begin{array}{l}73 \\
17\end{array}$ & $\begin{array}{l}81.1 \\
18.9\end{array}$ & 7.716 & 0.120 \\
\hline $\begin{array}{c}\text { Frequency of vaginal douching } \\
\text { Once a week } \\
2-3 \text { times a week }\end{array}$ & $\begin{array}{l}23 \\
40\end{array}$ & $\begin{array}{l}36.5 \\
63.5\end{array}$ & $\begin{array}{l}23 \\
50\end{array}$ & $\begin{array}{l}31.5 \\
68.5\end{array}$ & 5.213 & 0.157 \\
\hline $\begin{array}{l}\text { Where she found out about vaginal } \\
\text { douching }\end{array}$ & & & & & & \\
\hline
\end{tabular}

Vol. 3 No. 2 November 2012 
Tanta Scientific Nursing Journal

\begin{tabular}{|c|c|c|c|c|c|c|}
\hline $\begin{array}{l}\text { from family elder } \\
\text { on her own } \\
\text { from friends }\end{array}$ & $\begin{array}{l}29 \\
18 \\
16\end{array}$ & $\begin{array}{c}46 \\
28.6 \\
25.4\end{array}$ & $\begin{array}{l}27 \\
30 \\
16\end{array}$ & $\begin{array}{l}37 \\
41 \\
22\end{array}$ & 5.44 & 0.142 \\
\hline $\begin{array}{c}\text { Materials used in vaginal douching } \\
\text { water } \\
\text { soap and water }\end{array}$ & $\begin{array}{l}20 \\
43\end{array}$ & & $\begin{array}{l}48 \\
25\end{array}$ & $\begin{array}{l}65.8 \\
34.2\end{array}$ & 18.77 & 0.000 \\
\hline $\begin{array}{c}\text { For what purpose? } \\
\text { After menstruation } \\
\text { After sexual intercourse } \\
\text { After a bath }\end{array}$ & $\begin{array}{c}26 \\
30 \\
7\end{array}$ & $\begin{array}{l}41.3 \\
47.6 \\
11.1\end{array}$ & $\begin{array}{l}18 \\
10\end{array}$ & $\begin{array}{l}61.6 \\
24.7 \\
13.7\end{array}$ & 5.96 & $* 0.460$ \\
\hline $\begin{array}{c}\text { Does she regularly rinse out the } \\
\text { vagina? } \\
\text { Yes } \\
\text { No }\end{array}$ & $\begin{array}{l}38 \\
25\end{array}$ & $\begin{array}{l}60.3 \\
39.7\end{array}$ & $\begin{array}{l}48 \\
25\end{array}$ & $\begin{array}{l}65.8 \\
34.2\end{array}$ & 7.63 & 0.020 \\
\hline $\begin{array}{c}\text { Manner in which vaginal douching is } \\
\text { done } \\
\text { Fingers + water at } \\
\text { high pressure } \\
\text { Water at high pressure }\end{array}$ & 11 & $\begin{array}{l}82.5 \\
17.5\end{array}$ & 20 & $\begin{array}{l}27.4 \\
72.6\end{array}$ & 29.05 & 0.000 \\
\hline $\begin{array}{c}\text { Is VD harmful? } \\
\text { Yes } \\
\text { No }\end{array}$ & $\begin{array}{l}18 \\
45\end{array}$ & $\begin{array}{l}28.6 \\
71.4\end{array}$ & 50 & $\begin{array}{l}31.5 \\
68.5\end{array}$ & 2.87 & 0.230 \\
\hline $\begin{array}{c}\text { Number of times a week she has sex } \\
\qquad \begin{array}{c}1-2 \\
3-4 \\
5 \text { and more }\end{array}\end{array}$ & $\begin{array}{c}43 \\
16 \\
4\end{array}$ & $\begin{array}{r}68.3 \\
25.4 \\
6.3\end{array}$ & $\begin{array}{l}50 \\
18 \\
5\end{array}$ & $\begin{array}{c}68.5 \\
24.7 \\
6.8\end{array}$ & 8.37 & 0.000 \\
\hline
\end{tabular}

*OCP: Oral Contraceptive

**ICUD: Intrauterine contraceptive device 
Table 3: Percentage Distribution of some hygienic characteristics of the women

\begin{tabular}{|c|c|c|c|c|c|c|}
\hline \multirow[t]{3}{*}{ Variables } & \multicolumn{4}{|c|}{ Groups } & \multirow{3}{*}{$\mathbf{X}^{2}$} & \multirow{3}{*}{$\mathbf{P}$} \\
\hline & \multicolumn{2}{|c|}{$* \mathrm{OCP}=90$} & \multicolumn{2}{|c|}{$* *$ IUDC $=90$} & & \\
\hline & No & $\%$ & No & $\%$ & & \\
\hline \multicolumn{7}{|l|}{$\begin{array}{l}\text { Post-toilet cleansing from } \\
\text { back to front }\end{array}$} \\
\hline Yes & 71 & 78.9 & 59 & 65.6 & 6.211 & 0.001 \\
\hline No & 19 & 21.1 & 31 & 34.4 & & \\
\hline \multicolumn{7}{|l|}{$\begin{array}{l}\text { Drying after going to the } \\
\text { Toilet }\end{array}$} \\
\hline Yes & 68 & 75.6 & 78 & 86.7 & 1.494 & 0.149 \\
\hline No & 22 & 24.4 & 12 & 13.3 & & \\
\hline \multicolumn{7}{|l|}{ Drying material } \\
\hline Toilet paper & 53 & 58.8 & 68 & 75.6 & 5.91 & 0.011 \\
\hline Cloth hand-sewn at home & 37 & 41.2 & 22 & 24.4 & & \\
\hline \multicolumn{7}{|l|}{ Cotton underwear? } \\
\hline Yes & 75 & 83.3 & 70 & 77.8 & 2.414 & 0.08 \\
\hline No & 15 & 16.7 & 20 & 22.2 & & \\
\hline \multicolumn{7}{|l|}{ Always uses a sanitary pad } \\
\hline Yes & 67 & 74.4 & 32 & 35.6 & 18.55 & 0,000 \\
\hline No & 23 & 25.6 & 58 & 64.4 & & \\
\hline \multicolumn{7}{|l|}{ Uncomfortable discharge } \\
\hline Yes & 56 & 62.2 & 37 & 41.2 & 3.85 & 0.001 \\
\hline No & 34 & 37.8 & 53 & 58.8 & & \\
\hline \multicolumn{7}{|l|}{ Daily water consumption } \\
\hline Less than 1 liter & 30 & 33.3 & 25 & 27.8 & & \\
\hline 2 liters & 50 & 55.6 & 45 & 50 & 9.956 & 0.007 \\
\hline More than 2 liters & 10 & 11.1 & 20 & 22.2 & & \\
\hline
\end{tabular}

*OCP: Oral Contraceptive

**ICUD: Intrauterine contraceptive device 
Tanta Scientific Nursing Journal

Table 4:Logistic regression analysis of variables affecting bacterial growth in urine culture

\begin{tabular}{|c|c|c|c|}
\hline \multirow{2}{*}{ Variables } & \multicolumn{2}{|c|}{} & \multirow{2}{*}{ P } \\
\cline { 2 - 3 } & Exp & 95\% CI Lower -Upper & \\
\cline { 2 - 3 } & & $0.01-0.92$ & 0.04 \\
\hline Oral Contraceptive & 0.13 & $0.34-71.21$ & 0.16 \\
\hline $\begin{array}{c}\text { Vaginal douching } \\
\text { front }\end{array}$ & 15.48 & $1.54-48.69$ & 0.01 \\
\hline $\begin{array}{c}\text { Continuous } \\
\text { use of sanitary } \\
\text { napkin }\end{array}$ & 8.67 & $40.83-7.68$ & 0.00 \\
\hline $\begin{array}{c}\text { Sexual } \\
\text { intercourse 3-4 } \\
\text { times a week }\end{array}$ & 59.99 & $0.55-0.75$ & 0.01 \\
\hline $\begin{array}{c}\text { Using a cloth } \\
\text { for drying off }\end{array}$ & 0.158 & & $0.02-1.22$ \\
\hline $\begin{array}{c}\text { Consuming } \\
\text { less than 2 } \\
\text { liters of water }\end{array}$ & 68.94 & $6.21-75-98$ & \\
\hline
\end{tabular}

*OCP: Oral Contraseptive

Table 5:

Logistic regression analysis of variables affecting bacterial growth

in the vaginal culture

\begin{tabular}{|c|c|c|c|}
\hline Variables & Exp & $\begin{array}{c}\text { 95\% CI Lower }- \\
\text { Upper }\end{array}$ & P \\
\hline IUCD & 1.07 & $0.49-2.35$ & 0.03 \\
\hline Vaginal douching & 6.47 & $0.97-42.74$ & 0.05 \\
\hline Performing VD & 0.69 & $0.29-1.61$ & 0.39 \\
\hline
\end{tabular}

Vol. 3 No. 2 November 2012 


\section{Tanta Scientific Nursing Journal}

\begin{tabular}{|c|c|c|c|}
\hline with the fingers & & & \\
\hline Performing VD & 1.68 & $0.77-3.65$ & 0.05 \\
$2-3$ times a week & & & 0.08 \\
\hline $\begin{array}{c}\text { Continuously using a sanitary } \\
\text { Napkin }\end{array}$ & 0.53 & $0.26-1.08$ & \\
\hline
\end{tabular}

**ICUD: Intrauterine contraceptive device

\section{DISCUSSION}

In the present study, there was a higher percentage $(81.1 \%)$ of women using IUCDs who were practicing VD compared to the women who were taking OCPs (70. \%). Many studies have shown that the use of IUCDs increases the risk of vaginal infection ${ }^{[22,23,25]}$. Various factors play a role in determining whether women using IUCDs will develop an infection. These are, among others, the technique used in inserting the IUCD, the duration of its use, and the age of the woman. The IUCD changes the nature of the vaginal flora and leads to an increase in anaerobic bacteria ${ }^{[17}$, 26].

However, many studies have also shown that genitourinary system infections are reduced if general hygiene is carefully practiced, the IUCD is carefully inserted, and regular check-ups are performed over the period the IUCD remains in the uterus, provided the rules of hygiene are adhered to ${ }^{[24,26]}$. As it was observed in the present study that women using IUCDs had better toilet hygiene behavior than the women taking OCPs, it might be said that hygiene is one of the factors affecting the growth of bacteria in the urine cultures of women taking OCPs.

Failure to clean the anal region separately leads to the colonization of microorganisms at the entry of the urethra and vagina ${ }^{[26]}$. Vaginal douching, the continuous use of sanitary napkins, and faulty washing and cleaning after defecation increases the risk of infection ${ }^{\{27,28]}$. 
Vaginal douching has become a part of women's general hygiene in ${ }^{[14,15]}$. Married women describe themselves as being soiled when seminal fluid remains in the vagina after sexual intercourse. Women's beliefs cause women to regard the vagina as contaminated after intercourse. Women practice vaginal douching to feel clean again and many studies have shown that women practice vaginal douching to restore their sense of wellness and cleanliness ${ }^{[10,18]}$. Other reasons reported as to why women perform vaginal douching have been vaginal discharge, eliminating itching or odor, preventing or treating sexually transmitted diseases or vaginal infections, and using the practice as a contraceptive measure ${ }^{[8,10,14,29]}$. The practice is common as it is a part of the full ablution regimen required by the religion after sexual intercourse. 4,10In the present study, VD was resorted to primarily after menstruation and sexual intercourse. Hodoğlugil et al. reported in a study they conducted in the Black Sea Region in 2000 that VD was practiced by $64.0 \%$ of women using IUCDs and by $64.5 \%$ of women that were not. In the present study, our finding was that more women with IUCDs were practicing VD compared to women taking OCPs; this is consistent with the literature.

In the study, the women in the OCP and IUCD groups said that they performed vaginal douching 2-3 times a week. In a sixmonth study conducted in the US, it was found that $22 \%$ of women practice vaginal douching ${ }^{[28]}$. The detergents, soaps, acetic acid, perfumes and other agents that may be used in vaginal douching disturb the vaginal flora and prepare a suitable environment for infection ${ }^{[10,16,29]}$. Various studies have shown that soap and water are the substances that are most commonly used in vaginal douching ${ }^{[6,14]}$.

In the present study, the use of soap and water was more pronounced in women taking OCPs compared with those using IUCDs. Most of the women taking OCPs were using their fingers to wash the vagina with soap and water whereas most of the women with IUCDs were practicing VD by washing out the vagina with water at high pressure without using the fingers. IUCDs in particular are a potential risk factor and although the women with IUCDs, who were 
using less soap than the OCP group and refraining from using their fingers, instead flushing out the area with water at high pressure, exhibited more prominent bacterial growth in the culture, both methods resulted in the development of vaginal infection The transport into the urinary tract of microorganism colonies developing in the vagina is facilitated by the fact that the exterior one-third of the urethra, which is short in women, is in constant contact with intestinal flora ${ }^{[26]}$. The regions of the body that are conducive to the colonization of microorganisms are the vagina, rectum, and ureter. The type of underwear worn, the form of cleansing, the materials used, among other factors, are all instrumental in the degree these three areas are protected ${ }^{[10]}$. Since the continuous use of a sanitary napkin keeps the vagina moist, an environment that allows bacteria to grow is thus created.

In many studies it has been shown that a large percentage of women use sanitary pads continuously, either because of religious beliefs or as a customary habit. It has been proven in many studies that daily water consumption can prevent urinary tract infections ${ }^{[17,26]}$. In our study, the predominance in the OCP group of uncomfortable vaginal discharge, cleansing from back to front, continuous use of sanitary napkins, daily water consumption of under 2 liters, and the use of cloths as drying materials after going to the toilet were the factors that resulted in more bacterial growth in the urine culture compared to the IUCD group. At the same time, it is known that estrogen facilitates the settling of uropathogens in the vagina and urogenital cells and that some antibiotics spoil the vaginal flora, creating an environment where microorganisms can grow freely ${ }^{[15,19]}$. The difference observed in the urine culture of women taking OCPs in the present study was a product of the characteristic of such agents, a factor which was intensified by the deficiencies in hygiene that were observed in the study.

\section{Conclusion and Recommendation}

Women continue to practice traditional habits that can be recognized as VD. Changing these traditions is a difficult task that will require time. VD is practiced, 
regardless of whether the hazards to the health are known or not. When the variety of reasons women practice VD are considered, it is of importance to study women's hygienic practices and educate them about the mistakes they are making. It is important that members of a health team offer women the opportunity for an exchange of information, working to prevent the complications that faulty technique and lack of attention to the rules of hygiene can bring about. The early discovery of mistakes is essential, not only in terms of preventing potential health problems in women but also in treating existing problems early on.

\section{REFERENCES}

1.Martino JL, Vermund SH. Vaginal douching 2002; Evidence for risks or benefits to women's health. Epidemiol. Rev 2002.;24:109-124.

2. Mete S, Gercek E. (2005): Factors affecting the prevalence of vaginal douching and outcomes. JOSN;55-61.

3. Lichtenstein, B., Nansel, T.R. 2000: Women's douching practices and related attitudes:findings from four focus groups. Women \& Health2000;30(4):117-131.
4. http://www.diyanet.gov.tr/ Accessed 12 February 2012

5. Ege E, Timur S, Zincir H, et alVaginal douching practices and related attitudes in eastern Turkey. J. Obstet. Gynaecol. Res 2007; 33(3):353-59.

6. Demirbağ C. Risk factors for IUCD related to hygienic habits in women. C.U. Nurs.School J.2000; 4(2):52-58.

7. Foch BJ, McDaniel ND, Chacko MR: Racial differences in vaginal douching knowledge, attitude, and practices among sexually active adolescents. JPAG 2001; $14: 29-33$

8. Hacıalioğlu N, Đnandı T, Pasinlioğlu T: Incidence of genital infections and risk factors in women presenting at the Erzurum Mother \& Child Health and Family Planning Center. A. U, Nurs. School J 2000;. 3(2):11-17.

9. Akın B, Erdem H, Ege E: Vaginal douching practices in married women, ages 15-49, and adverse effects. Life Sci. J 2006;3 3 .

10. Calıskan D, Subası N, Sarısen O.: Vaginal douching and associated factors among married women attending a family 
planning and gynecology clinic. 4th International Congress of Reproductive Health \& Family Planning, Bayt press Ankara: Turkey, 2006'.201-205.

11. Martino JL, Vermund SH.Vaginal douching: Evidence for risks or benefits to women's health. Epidemiol. Rev.2002; 24:109-124.

12. Simpson T, Merchant JS, Grimley DM, et al. (2004):Vaginal douching among adolescent and young women: more challenges than progress. J Pediatr Adolesc Gynecol 2004; 17:249- 258.

13. Kirchner JT.: Prevalence of vaginal douching despite its adverse effects.

Am.Fam.Phys. 2000;61(3):849-851.

14. Calzolari E, Masciangelob R, Militea V. et al: Bacterial vajinosis and contraceptive methods. Int $\mathrm{J}$ Gynaecol Obstet2000.;70:341-46.

15. Calıskan D, Col M, Akdur R, et al. Study of prevalence of vaginal douching in women, ages 15-49, in the Park Regional Healthcare Center and influencing factors, Ankara University Medical School Journal2003;49(2):73-80.
16. Kalterna V, Tepes NK, Pejkovic L et al. An intrauterine device as a possible cause of change in the microbial flora of the female genital system. J Obstet. Gynaecol. Res.2011; 37(8):1035-1040.

17. Gupta K, Hiller SL, Hooton TM et al. Effects of contraceptive method on the vajinal microbial flora: A prospective evaluation. J Infect. Dis. 2000;181:59597.

18. Anh PK, Khanh NT, Ha DT, et al.(2003): Prevalence of lower genital tract infection among women attending maternal and child health and planning clinics in Hanoi. Vietnam, Southeast Asian J Trop Med Public Health;34:367373.

19. Oh MK, Funkhouser E, Simpson T, et al. Early onset of vaginal douching is associated with false beliefs and high risk behaviour. STDs 2003;30(9):689-669.

20. Zarakolu P, Hodoglugil NS, Aydın F, et al.: Reliability of interpretation of gramstained vaginal smears by nugent's scoring system for diagnosis of bacterial vaginosis. Diagn. Microbiol. and Infect.

Dis.2004; 48(2):77-80. 
21. Turkish Population and Health Research

On Rapor. Tubitak Mart: Ankara, 2009.

22. Gazmararian JA, Bruce FC, Kendrick JS, et al: Why do women douche? Results from a qualitative study. Matern Child Health J2001; 5(3):153-159.

23. Chiaffarino F, Parazzini F, DeBesi P: Risk factor for bacterial vaginozis. Eur J. Obstet. Gynecol Reprod. Bio 12004.;117:222-226.

24. Calıskan D. Traditional intravaginal applications: "should vaginal douching, lavage be performed or not? $\mathrm{CME}$ 2005;4:15-18.

25. Ocak S, Cetin $M$, Hakverdi $S$. et alEffects of intrauterine device and oral contraceptive on vaginal flora and epithelium. Saudi Med. J2007.;28:727-31.

26. Ozsut H.Urinary tract infections: Infectious Diseases and Clinical Microbiology2002; 1059-65. Ayse Wilke Topcu, Guner Soyletir, Mehmet Doğanay (Eds), Nobel medical press,

27. Hoduoglugul NS, Aslan D, Bertan M. .Intrauterine device use and some issues related to sexually transmitted disease screening and occurrence. Contraception 2000;61:359-364.

28. Koumans EH, Stenberg M, Bruce $\mathrm{C}$ et al. The prevalence of bacterial vaginosis in the United States, 2001-2004; associations with symptoms, sexual behaviors, and reproductive health. Sex Transm. Dis.2007;;34:864-9.

29. Pavlova SI, Tao L.In vitro inhibition of commercial douche products against vaginal microflora. Infect Dis Obstet Gynecol.2002;;8:99-104. 